\title{
Electroantennogram Responses of the Onion Fly, Hylemya antiqua MeIGEN (Diptera: Anthomyiidae) to Oviposition Stimulants
}

\author{
Yukio IsHIKAWA \\ Laboratory of Applied Entomology, Faculty of Agriculture, \\ University of Tokyo, Bunkyo-ku, Tokyo 113, Japan
}

(Received February 4, 1988)

\begin{abstract}
Electrophysiological investigation of the antenna of the onion fly, Hylemya antiqua MeIGEN was made in relation to the specific oviposition stimulativeness of the propylthio compounds. 1. The compounds with a propylthio moiety elicited high electroantennogram (EAG) responses in general, though some non-stimulants also raised high EAG responses. 2. EAG responses for sulfur compounds were similar to those obtained with single cell recordings from DNPD cells, a group of cells characterized by responsiveness to dipropyl disulfide. 3. Analysis of dose-EAG response regression lines for oviposition stimulants and related non-stimulants indicated that all oviposition stimulants are received by the same receptor. 4. It was thus concluded that the specific oviposition stimulativeness of the propylthio compounds can be explained in part by the specificity of olfactory receptors on the antenna.
\end{abstract}

\section{INTRODUCTION}

Many studies on electroantennogram (EAG) and single cell responses of phytophagous insects to plant constituents have been made to reveal the insect-plant relationships at the sensory organ level (GuERIn and STÄDler, 1982; HondA, 1986; HondA and IsHIKAWA, 1987; VISSER, 1986). EAG is a generally useful tool for elucidating an insect's olfaction repertoire, though single cell recording is necessary for further information such as odor quality coding. For instance, by coupling gas chromatography and EAG as a detector (GC-EAD), GuERIN et al. (1983) identified host plant attractants for the carrot fly, Psila rosae as trans-methylisoeugenol, trans-asarone, hexanal, $(E)$-2hexenal and heptanal.

As oviposition stimulants of the onion fly, Hylemya antiqua, we have revealed by chemical analysis of onion odor and subsequent laboratory bioassay that the propylthio compounds such as dipropyl disulfide, methyl propyl disulfide emanating from onion stimulate oviposition (Ishikawa et al., 1978). With single cell recording from the antennal olfactory cells, HoNDA et al. (1987) showed the presence of two types of cells: one is characterized by responsiveness to di-n-propyl disulfide (DNPD cells), and the other to ethyl acetate (EA cells). The objective of the present research was to learn by EAG analysis whether the oviposition stimulativeness of the propylthio compounds to the onion fly could be attributed to the presence of specific olfactory receptors on the antenna. 


\section{MATERIALS AND METHODS}

Antennectomy. The onion flies used in this study were obtained from the Hokkaido National Agricultural Experiment Station and reared for several years in our lab. The larvae were reared on onions to avoid possible occurrence of an induced preference for foreign substances when reared on an artificial diet.

Gravid female flies between 14 and 25 days old were anesthetized by placing them in a refrigerator for $10 \mathrm{~min}$. Either or both antennae were pinched off at the pedicel with fine forceps under a binocular microscope. The control flies were given anesthetization only. After complete recovery from the treatment, the flies were subjected to the bioassay.

Bioassay. Twenty-five treated females and the same number of intact males were put in a $30 \times 30 \times 30 \mathrm{~cm}$ cubic cage. Bioassay procedure was the same as described by IshikawA et al. (1978): two $9 \mathrm{~cm}$ glass petri dishes with a $6 \mathrm{~mm}$ layer of glass beads were used as oviposition substrate. A piece of onion was put in one dish as an oviposition stimulant whereas the other dish had none. The flies were kept in the cage containing the petri dishes for $20 \mathrm{hr}$ for oviposition and the number of eggs laid was then counted. The difference in number of eggs laid between the treated and the control was regarded as oviposition stimulativeness.

Test chemicals. Thiols and symmetric sulfur compounds such as dipropyl and diethyl disulfides were commercial products of reagent grade. Asymmetric sulfides and disulfides, e.g., propyl phenyl sulfide, propyl amyl disulfide, were synthesized by the method described in Ishikawa et al. (1978), and finally purified by preparative gas chromatography to a purity of over $99 \%$.

$E A G$ recording. Flies were immobilized by cooling and the heads were cut off with a razor blade. They were placed with the cut end down on a sheet of $0.1 \mathrm{M} \mathrm{KCl}$ soaked tissue paper covering a small platform in a petri dish. As a recording electrode, a glass capillary (ca. $10 \mu \mathrm{m}$ at the tip) filled with $0.1 \mathrm{M} \mathrm{KCl}$ was connected with an Ag$\mathrm{AgCl}$ wire to the probe of a microelectrode preamplifier (MEA-8101, Nihon Koden). The distal end of the antenna was touched with the glass electrode using a micro manipulator (MM-333, Narishige) under a binocular microscope (MO-8, Wilde). As an indifferent electrode an $\mathrm{Ag}-\mathrm{AgCl}$ wire was attached to the moistened tissue paper. Receptor potential was fed to a biophysical amplifier (AVB-10, Nihon Koden) with high-cut filter $(30 \mathrm{~Hz})$ and displayed on a memory oscilloscope (VC-10, Nihon Koden). Both antennae from at least 4 different flies were used and each antenna was tested twice for a series of compounds. A 1-min interval was allowed between stimulations.

Test chemicals were diluted with ether successively ( $1 / 10$ at vol/vol basis) to make concentrations of $10^{-4}$ to $10 \mu \mathrm{l}$ test chemicals per $100 \mu \mathrm{l}$ ether. Each solution $(100 \mu \mathrm{l})$ was applied to a piece of filter paper $(1 \mathrm{~cm} \times 1.5 \mathrm{~cm})$ lining the inside of a glass cartridge (1-cm diam. $\times 1.5 \mathrm{~cm}$ long). After evaporation of the ether, the cartridge was put in a $5 \mathrm{ml}$ injector and left for a few minutes so that complete equilibrium of the test chemical between the filter paper and the air within the syringe was attained. A constant air flow $(1,000 \mathrm{ml} / \mathrm{min})$ was made by pumping the air through columns of charcoal and silica gel. The nozzle of the air flow tube was set $1.5 \mathrm{~cm}$ apart from the antenna. Three $\mathrm{ml}$ of air containing the test chemical was injected into the air flow by quickly depressing the plunger of the syringe manually. 


\section{RESULTS AND DISCUSSION}

\section{Confirmation of the reception of oviposition stimulants by the antennae}

To study relationships between certain behavioral response and electrophysiological data, it is a prerequisite to confirm that the organ under study is the sole or major one receiving the stimulant, and is responsible for eliciting the behavior. In the onion fly, the antennae are considered to have this function, however, the involvement of other olfactory organs cannot be excluded. Thus, oviposition response of antennectomized flies was first investigated (Table 1). The bilaterally treated flies laid only 19 eggs in total, whereas the unilaterally treated or intact flies laid about 160 eggs. Furthermore, the former oviposited only 11.8 eggs to an onion piece, which was fewer than the number oviposited to the controls by the latter, 23.2 and 34.2 . This result clearly demonstrated that the antennae are the primary organ receiving the oviposition stimulants.

\section{Dose-EAG response relationships}

First, the EAG response to dipropyl disulfide (PrSSPr), an oviposition stimulant, was examined (Fig. 1). The EAG response increased linearly with the logarithm of dose in a range of $10^{-4}$ to $10 \mu \mathrm{l} /$ filter paper, though the responses to higher doses were quite variable. The amplitude of EAG ranged from $0.4 \mathrm{mV}$ at the dose of $10^{-4} \mu \mathrm{l}$ to $4.8 \mathrm{mV}$ at $10 \mu \mathrm{l}$. Thereafter, $0.1 \mu \mathrm{l}$ of test chemicals was used as the standard dose

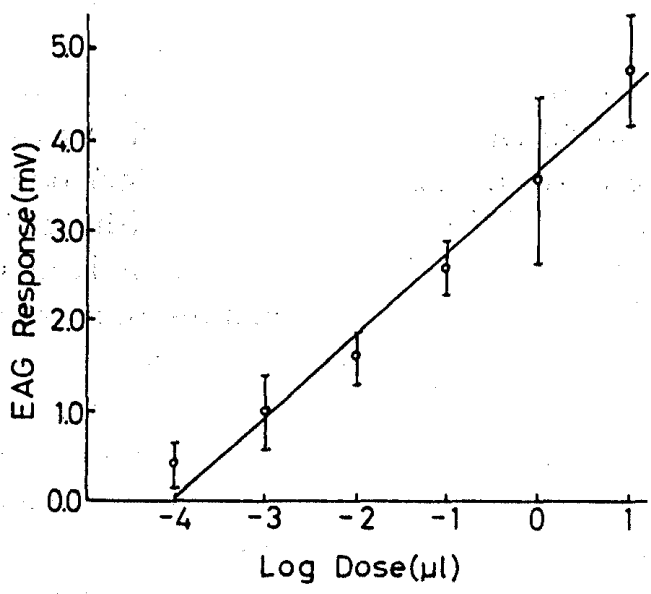

Fig. 1. EAG responses of the female onion fly, Hylemya antiqua to an oviposition stimulant, dipropyl disulfide (PrSSPr).

Table 1. Effect of antennectomy on oviposition of the onion fly, Hylemya antiqua MEIGEN

\begin{tabular}{cccc}
\hline $\begin{array}{c}\text { Oviposition } \\
\text { Stimulant }\end{array}$ & Untreated & $\begin{array}{c}\text { Unilaterallya } \\
\text { antennectomized }\end{array}$ & $\begin{array}{c}\text { Bilaterally } \\
\text { antennectomized }\end{array}$ \\
\cline { 2 - 4 } & $135.2^{*}$ & $133.0^{*}$ & 11.8 \\
A piece of onion & 23.2 & 34.2 & 7.4 \\
None (control) & 158.4 & 167.2 & 19.2 \\
Total & &
\end{tabular}

2 Second and third segments of the antennae were cut off.

* Significantly different from respective control at 5\% level. 


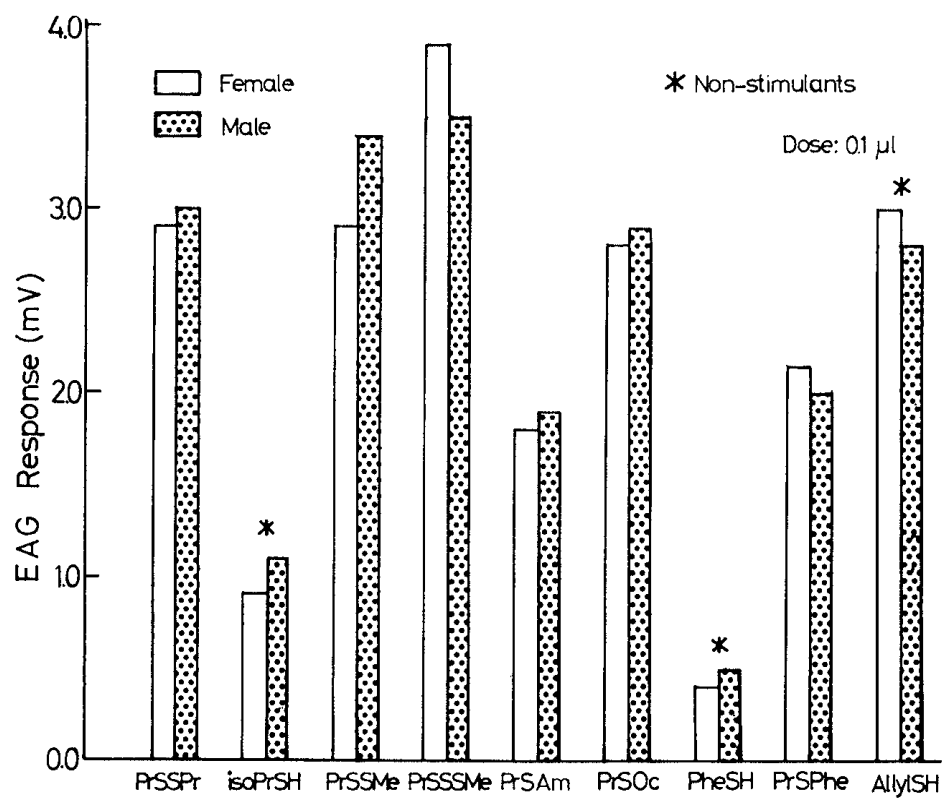

Fig. 2. EAG responses of the onion fly to several sulfur compounds with a propylthio moiety (oviposition stimulant) and those without it (non-stimulant). For abbreviation of compounds, see Table 2.

except for $n$-alcohols $(1.0 \mu \mathrm{l})$. As shown later, males gave almost the same responses as females.

The dose-response relationship is similar to the result obtained with single cell recording from DNPD cells (Honda et al., 1987). Olfactory threshold for PrSSPr was almost the same in EAG response and single cell recording: between $10^{-5}$ and $10^{-4} \mu \mathrm{l} /$ filter paper.

\section{Specificity of antennal olfactory cells to the oviposition stimulants}

EAG responses to several sulfur compounds with a propylthio moiety (oviposition stimulants), and those without it (non-stimulants) are shown in Fig. 2. All of the propylthio compounds elicited high levels of EAG response, i.e. over $2 \mathrm{mV}$ when the dose was $0.1 \mu \mathrm{l}$. Though propyl amyl sulfide, propyl octyl sulfide and propyl phenyl sulfide are not present in onion volatiles, they not only stimulated oviposition (IsHIKAwA et al., 1978), but also elicited high EAG responses. On the other hand, nonstimulants, iso-propylthiol and phenylthiol, induced low EAG response by themselves. However, when phenylthiol was chemically modified to have a propyl group, the product propyl phenyl sulfide not only became behaviorally active but also demonstrated a high EAG response (Fig. 2). Allylthiol was an exception: despite the lack of a propylthio moiety, this chemical elicited almost the same EAG response as other propylthio compounds. From these results it may be said that propylthio compounds elicit high EAG responses in general though the level is affected by the structure of the rest of the molecule.

There were no significant differences between the EAG responses of females and males (Fig. 2). 


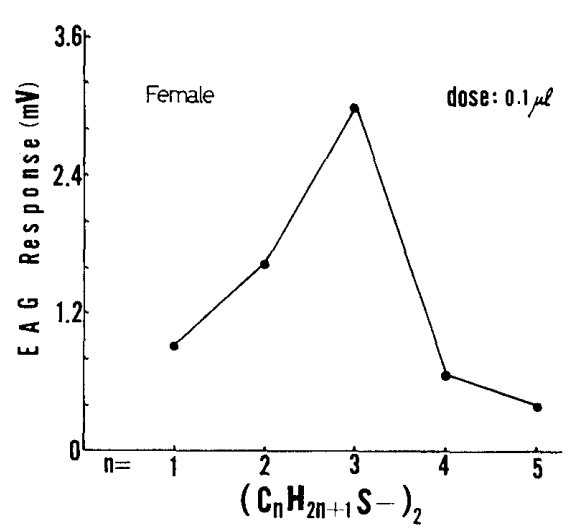

Fig. 3. EAG responses of the onion fly to a series of dialkyl disulfides with increasing alkyl chain length.

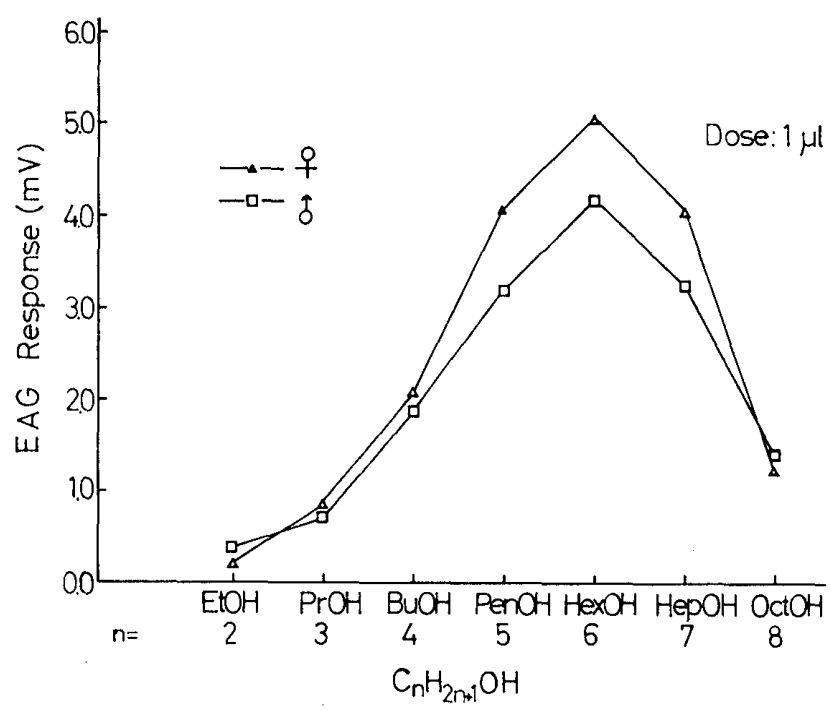

Fig. 4. EAG responses of the onion fly to a series of $n$-alcohols with increasing alkyl chain length. Dose: $1 \mu 1$.

\section{Specificity of olfactory cells to a propyl group}

EAG responses to a series of dialkyl disulfides with increasing alkyl chain length were compared to determine the specificity of the antennal olfactory cells to a "propyl" group (Fig. 3). The response increased as the chain lengthened, reached maximum at 3 carbons ( $\mathrm{PrSSPr}$ ), and then decreased sharply as the chain lengthened further. This result cannot be explained by the differences in volatility of chemicals because both dimethyl and diethyl disulfide have much higher volatility than does PrSSPr. Since PrSSPr is the only strong oviposition stimulant among these chemicals (IsHIKAWA et al., 1978), this result is in good accordance with the behavioral specificity of onion fly to propylthio compounds, which are major constituents of onion volatiles. Though nonstimulants also elicited some EAG responses, these responses at the sensory cells may fade out through "olfactory coding" at the brain level (BoEckH and ERNst, 1987; KAFKA, 1987).

The EAG response profile for dialkyl disulfides is similar to that obtained by single cell recording from DNPD cells, though relative response to dimethyl and diethyl disulfides is higher and to dibutyl disulfide is lower than that result (Honda et al., 1987). This difference in responses between EAG and single cell recording may indicate the presence of other types of cells than DNPD cells that respond to dialkyl disulfides.

\section{$E A G$ responses to straight chain alcohols}

EAG responses to several alcohols with varying alkyl chain length were tested to see whether the specificity for the propyl group could be observed in alcohols as well (Fig. 4). Unlike the sulfur compounds, EAG response reached maximum at 6 carbons. High EAG response to six-carbon alcohols seems to be a common phenomenon in insects: carrot fly (GUERIN and Visser, 1980), American cockroach (Nishino and Washio, 1976) and yellow peach moth (Honda et al., 1986). The differential EAG 
Table 2. EAG responses and relative oviposition stimulativeness of synthetic propylthio compounds ${ }^{a, b}$

\begin{tabular}{lcc}
\multicolumn{1}{c}{ Compound } & $\begin{array}{c}\text { EAG } \\
\text { response }\end{array}$ & $\begin{array}{c}\text { Oviposition } \\
\text { stimulativeness }^{\mathbf{c}}\end{array}$ \\
\hline Dipropyl disulfide (PrSSPr) & 1.00 & 1.00 \\
Propyl methyl disulfide (PrSSMe) & 1.16 & 1.02 \\
Propyl amyl disulfide (PrSSAm) & 1.01 & 0.95 \\
Propyl amyl sulfide (PrSAm) & 0.72 & 0.69 \\
Propyl octyl sulfide (PrSOc) & 0.71 & 0.34 \\
Propyl phenyl sulfide (PrSPhe) & 0.60 & 0.48 \\
Propyl methyl trisulfide (PrSSSMe) & 1.17 & 0.46 \\
\hline
\end{tabular}

a EAG response and number of eggs laid for PrSSPr were set as 1.0 for comparison.

b Correlation coefficient between the two responses is 0.53 (it becomes 0.90 when the response to PrSSSMe is excluded).

c Data calculated from Ishikawa et al. (1978).

responses of onion fly to alcohols and disulfides may indicate the difference in receptors that receive these chemicals.

With single cell recording, HoNDA et al. (1987) showed that DNPD and EA cells have different response profiles to a series of alcohols: DNPD cells were more responsive to heptanol and octanol, while the EA cells were to pentanol and hexanol. However, EAG recordings revealed no bimodality in response. This may suggest that many types of cells are responsive to $n$-alcohols.

Relationships between EAG response and oviposition stimulativeness of the propylthio compounds

Since EAG is a summed response of all kinds of receptors on the antenna (BoECKH et al., 1965; MAYER et al., 1984), it naturally cannot predict the oviposition stimulativeness of chemicals in general (IKeshojl et al., 1981). However, there remains some possibility that EAG responses and oviposition stimulativeness are correlated within the propylthio compounds. As shown in Table 2, there was only a low correlation $(r=0.53)$ between the relative oviposition stimulativeness and the relative intensity of EAG responses. However, the correlation became very high $(r=0.90)$ when a trisulfide (PrSSSMe) was excluded. This exceptional compound elcited a high EAG response though oviposition stimulativeness was low (Table 2). At present the reason for this anomaly of PrSSSMe is unknown.

\section{Olfactory receptor for the oviposition stimulants}

To analyze the specificity for the oviposition stimulants at the olfactory receptor level, the dose-EAG response regression lines of the stimulants (PrSSPr, PrSSAm and PrSPhe) and the related non-stimulants (AmSSAm, PheSH) were studied in detail. As shown in Fig. 5, the regression line of PrSSAm is similar to that of PrSSPr, whereas those of PheSH and AmSSAm are quite different from it. The regression line of PrSPhe lies between those of PrSSPr and PheSH.

Attempts have been made to determine if two odors act on the same or a different kind of receptor by the analysis of dose-EAG response curves of binary odorant mixtures. It is now acknowledged that if two kinds of compounds are received by independent receptors, the regression line for the mixture of the two compounds becomes the sum of 


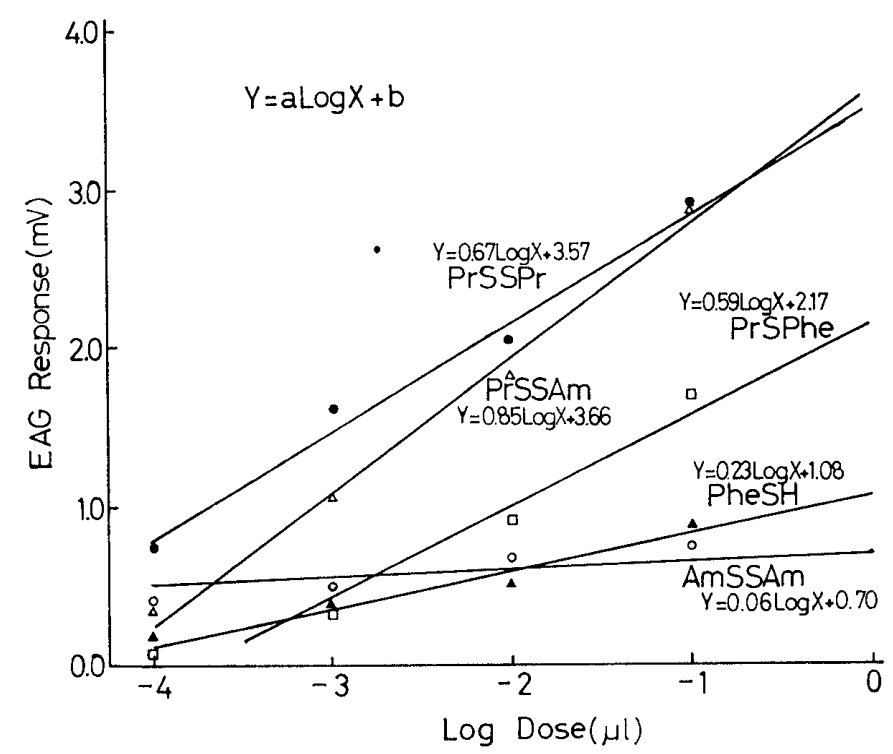

Fig. 5. Dose-EAG response regression lines for the stimulants (PrSSPr, PrSSAm, PrSPhe) and the related non-stimulants (AmSSAm, PheSH).

those for each one (Borst, 1984; Guerin et al., 1983). By contrast, the slopes of the regression lines of two compounds which interact with the same receptor are expected to be identical, though the intercepts with the abscissa may differ depending on the affinity between the molecule and the receptor (BORsT, 1984).

PrSPhe and PrSSAm possibly have interaction with the receptor for PrSSPr (PrS-receptor) because their slopes are very close to that of PrSSPr. On the contrary, AmSSAm and PheSH do not likely have interaction with the PrS-receptor as the slopes are very small compared with that of PrSSPr. PrSSAm may also have interaction with receptors other than that for PrSSPr because the slope value for PrSSAm (0.85) is greater than that for PrSSPr (0.67).

Furthermore, the difference of intercepts with the abscissa shows that the affinity of PrSSAm to the receptor is comparable to that of PrSSPr, whereas that of PrSPhe to the receptor is very low. This low affinity of PrSPhe with the PrS-receptor may be explained in part by the presence of a bulky aromatic ring, which sterically hinders the accommodation of the molecule by the receptor.

In conclusion, the asymmetric compounds with a prophylthio moiety seem to interact with the same kind of receptor that receives PrSSPr, but to different degrees of affinity depending on the structure of the remainder of a molecule.

\section{ACKNOWLEDGEMENTS}

The author wishes to express his sincere thanks to Prof. Y. MAtsumoto and Associate Prof. T. IkeshojI of his laboratory for their encouragement during the study.

\section{REFERENCES}

BozGKH, J. and K.-D. ERNsr (1987) Contribution of single unit analysis in insects to an understanding of olfactory function. J. Comp. Physiol. 161 : 549-565. 
Boegkh, J., K. E. Kaissling and D. Schneider (1965) Insect olfactory receptors. Cold Spring Harbor Symposia on Quantitative Biology. 30: 263-280.

Borst, A. (1984) Identification of different chemoreceptors by electroantennogram recording. J. Insect Physiol. 30: 507-510.

Guerin, P. M. and E. StÄDler (1982) Host odour perception in three phytophagous Diptera-A comparative study. Proc. 5th Int. Sym. Insect-Plant Relationships, Wageningen Pudoc (J. H. Visser and A. K. Minks, eds.). pp. 95-105.

Guerin, P. M., E. StÄdler and H. R. Buser (1983) Identification of host plant attractants for the carrot fly, Psila rosae. J. Chem. Ecol. 9: 843-861.

Guerin, P. M. and J. H. Visser (1980) Electroantennogram responses of the carrot fly, Psila rosae, to volatile plant components. Physiol. Entomol. 5: 111-119.

Honda, H. (1986) EAG responses of the fruit- and Pinaceae-feeding type of yellow peach moth, Conogethes punctiferalis (GuENÉE) (Lepidoptera: Pyralidae) to monoterpene compounds. Appl. Ent. Zool. 21: $399-404$.

Honda, I. and Y. Ishrawa (1987) Electrophysiological studies on the dorsal and anterior organs of the onion fly larva, Hylemya antiqua Meigen (Diptera: Anthomyiidae). Appl. Ent. Zool. 22: 410-416.

Honda, I., Y. Ishikawa and Y. Matsumoto (1987) Electrophysiological studies on the antennal olfactory cells of the onion fly, Hylemya antiqua Meigen (Diptera: Anthomyiidae). Appl. Ent. Zool. 22: 417-423.

Honda, H., Y. Maruyama and Y. Matsumoto (1986) Comparison in EAG response to $n$-alkyl compounds between the fruit- and Pinaceae-feeding type of yellow peach moth, Conogethes punctiferalis (Guenée) (Lepidoptera: Pyralidae). Appl. Ent. Zool. 21 : 126-133.

Ikeshoji, T., Y. Ishikawa and Y. Matsumoto (1981) Behavioral and EAG synergism of various compounds to dipropyl disulfide in the ovipositional attraction of the onion fly, Hylemya antiqua MEIGEN (Diptera: Anthomyiidae). Appl. Ent. Zool. 16: 432-442.

Ishikawa, Y., T. Ikeshoji and Y. Matsumoto (1978) A propylthio moiety essential to the oviposition attractant and stimulant of the onion fly, Hylemya antiqua Meigen. Appl. Ent. Zool. 13: 115-121.

KAFKA, W. A. (1987) Similarity of reaction spectra and odor discrimination: single receptor cell recordings in Antheraea polyphemus (Saturniidae). J. Comp. Physiol. 161: 867-880.

Mayer, M. S., R. W. Mankin and G. F. Lemire (1984) Quantitation of the insect electroantennogram: Measurement of sensillar contributions, elimination of background potentials, and relationship to olfactory sensation. J. Insect Physiol. 30: 757-763.

Nishino, C. and H. Washio (1976) Electroantennograms of the American cockroach (Orthoptera: Blattidae) to odorous straight chain compounds. Appl. Ent. Zool. 11: 222-228.

Visser, J. H. (1986) Host odor perception in phytophagous insects. Ann. Rev. Entomol. 31: 121-144. 